\title{
Photodynamic therapy combined with intravitreal bevacizumab for the management of choroidal neovascularization resistant to bevacizumab monotherapy. A case series
}

\section{Terapia fotodinámica combinada con bevacizumab intravítreo para el tratamiento de neovascularización coroidea refractaria a tratamiento con monoterapia con bevacizumab, Serie de casos}

\author{
Gerardo Garcia-Aguirre ${ }^{1,2 *}$, Juan C. Romo-Aguas ${ }^{1}$, Abril Santos-Palacios ${ }^{1}$, Andree Henaine-Berra ${ }^{1}$, \\ Raul Velez-Montoya ${ }^{1}$ and Jans Fromow-Guerra ${ }^{1}$
}

${ }^{1}$ Departmento de Retina, Asociación para Evitar la Ceguera en México, Ciudad de México, México; ${ }^{2}$ Escuela de Medicina, Tecnológico de Monterrey, Ciudad de México, México

\begin{abstract}
Purpose: To evaluate the clinical response of treatment-resistant choroidal neovascularization (CNV) to photodynamic therapy (PDT) combined with bevacizumab (BVZ) therapy. Methods: Retrospective, non-comparative evaluation of eyes diagnosed with CNV secondary to age-related macular degeneration that had no response after at least 3 intravitreal BVZ injections, who were treated with combined PDT+BVZ therapy, followed by subsequent monthly BVZ for a 6 months period. Main outcome measures were best-corrected visual acuity (BCVA) and central macular thickness (CMT) during a 6 month follow-up period after combined therapy. Results: Eleven patients (54.5\% female, mean age 62 years) were included. Using ICG angiography, lesions were classified as polypoidal choroidal vasculopathy (PCV) 54.5\%, arteriolized CNV $18.2 \%$ (2), and non-differentiable $27.3 \%$ (3). BCVA (logMAR) at baseline was 0.63 (20/85), increasing to 0.32 (20/40) 6 months after treatment $(p=0.04)$. Mean CMT before the intervention was $469 \mu \mathrm{m}$, decreasing to $289 \mu \mathrm{m} 6$ months after treatment $(p=0.01)$. Conclusion: Combined $P D T+B V Z$ therapy appears to be effective in treatment-resistant $C N V$, with an improvement of BCVA and CMT after a 6-month period that was not observed with BVZ monotherapy. A high incidence of PCV and arteriolized CNV was observed in this group or treatment-resistant CNV cases. Terapia fotodinámica combinada con bevacizumab intravítreo para el tratamiento de neovascularización coroidea refractaria a tratamiento con monoterapia con bevacizumab, Serie de casos.
\end{abstract}

Key words: Bevacizumab. Photodynamic therapy. Choroidal neovascularization.

\section{Resumen}

Propósito: Evaluar la respuesta clínica de terapia fotodinámica (TFD) combinada con bevacizumab intravítreo (BVZ) en neovascularizaciones coroideas (NVC) resistentes a tratamiento posterior a un seguimiento de 6 meses. Métodos: Estudio retrospectivo, no comparativo de ojos con diagnóstico de NVC secundaria a degeneración macular relacionada a la edad con al menos 3 inyecciones de BVZ sin respuesta clínica, a los que se administró TFD+BVZ y posteriormente BVZ mensual por 6 meses. Las variables principales de desenlace incluyeron agudeza visual mejor corregida (AVMC) y grosor macular Correspondence:

Gerardo Garcia-Aguirre

Av. Vicente García Torres, 46

Col. S. Lucas Coyoacán

Date of reception: 13-07-2017

Date of acceptance: 24-11-2017

DOI: 10.24875/RMOE.M18000002
Available online: 16-07-2018 Rev Mex Oftalmol (Eng). 2018;92(4):152-158 www.rmo.com.mx 
central (GMC) durante un seguimiento de 6 meses posteriores al tratamiento combinado. Resultados: Se incluyeron 11 ojos de 11 pacientes (54.5\% femenino, edad promedio 62 años). Usando angiografía con ICG, se encontraron 6 casos de vasculopatía coroidea polipoidea (VCP) (54.4\%), 2 de NVC arteriolizada (18.2\%) y 3 casos sin patrón diferenciable (27.3\%). La AVMC (logMAR) basal fue de 0.63 (20/85), mejorando a 0.32 (20/40) después de la terapia combinada ( $p=0.04)$. El GMC basal fue de $469 \mu \mathrm{m}$, mejorando a $289 \mu \mathrm{m}$ después del tratamiento combinado $(p=0.01)$. Conclusión: La TFD combinada con BVZ puede ser efectiva en casos de NVC resistentes a tratamiento, con mejoría en la AVMC y el GMCterapia combinada parece ser efectiva para CNV resistentes a tratamiento con mejoría de BCVA y CMT posterior a 6 meses e tratamiento. La adecuada clasificación del tipo de CNV asociadas a una elevada resistencia puede ser útil para el tratamiento.

Palabras Clave: Bevacizumab. Terapia fotodinámica. Neovascularización coroidea.

\section{Introduction}

Age-related Macular Degeneration (AMD) is one of the leading causes of blindness in adults over 50 years in developed countries. Neovascular AMD, which represents only the $15 \%$ of all cases of AMD, is responsible for $80 \%$ of the AMD-related vision loss'.

Anti-vascular endothelial growth factor (anti-VEGF) agents (bevacizumab [BVZ], ranibizumab [RBZ] or aflibercept) are currently the first line of treatment for choroidal neovascularization (CNV) associated with AMD, showing a significant improvement in visual acuity $(V A)^{2}$. However, some cases do not achieve the desired outcome, despite monthly treatment with anti-VEGF monotherapy. There is no known cause for this phenomenon, but some studies have described a hypothesis, which is that non-responder cases are due to atypical variants of CNV, such as polypoidal choroidal vasculopathy (PCV), retinal angiomatous proliferation (RAP) or CNV with mature or arteriolized vessels. These variants of CNV may be readily diagnosed using indocyanine green angiography (ICG-A) $)^{3,4}$.

According to the American Society of Retina Specalists preferences and trends survey ${ }^{5}$, most retina specialists are keen to switch to another anti-VEGF agent when faced with a treatment-resistant CNV, usually after 3 to 6 injections without adequate clinical response. It has been previously suggested that the combination of photodynamic therapy (PDT) plus anti-VEGF agents could play a role in these non-responder cases $^{6}$. Other studies, however, have not shown significant improvement by using combined treatment versus anti-VEGF therapy alone ${ }^{7,8}$.

These patients suffer a great burden that affects various aspects of their life because even after receiving prompt and adequate treatment, there is no significant improvement, creating frustration in both the patient and the clinician.

Our purpose in this retrospective analysis was to evaluate the clinical response of treatment-resistant
CNV to a combination of photodynamic therapy (PDT) with monthly BVZ therapy.

\section{Methods \\ Patients}

This retrospective, interventional, non-comparative case series on Mexican population performed at the Asociación Para Evitar la Ceguera en México I.A.P. followed the tenets of the Declaration of Helsinki and obtained approval by the institutional ethics committee. Data were obtained from patients with diagnosis of CNV secondary to AMD that were unresponsive to BVZ monotherapy in the retina department from January 2012 to January 2015.

To be considered eligible for the analysis, patients had to have at least 3 anti-VEGF applications on a monthly basis (with an interval between injections no less than 4 weeks or longer than 6 weeks) with no significant improvement and at least 6 follow-up visits after combined PDT-BVZ. Poor response was defined as persistent intraretinal or subretinal fluid, with a reduction of the macular thickness of less than $25 \%$ and non-responders were defined as progressive deterioration of the VA > 5 letters, both after at least 3 injections of anti-VEGF agents, based on the de system proposed by Amoaku, $2015^{\circ}$. All subtypes of CNV were included and classified according to Fluorescein angiography (FA) and ICG-A patterns. Exclusion criteria were CNV lesions from other pathologies, such as pathologic myopia or angioid streaks; myopia greater than -6.00 $D$, concomitant retinal vascular disorders, recent surgery in the study eye and previous treatment with verteporfin.

\section{Treatment and follow up}

At each visit, patients underwent a complete ophthalmologic examination with dilated fundus and macular 
examination. Best corrected VA (BCVA) was measured with Early Treatment Diabetic Retinopathy Study (ETDRS) Charts. Central Macular Thickness (CMT) was determined by OCT (Heidelberg Spectralis, Heidelberg, Germany). Once patients were diagnosed with a treatment-resistant CNV and classified by ICG-A and FA; they received a combined PDT+BVZ therapy. When patients received PDT, they received an intravenous infusion of verteporfin $(6 \mathrm{mg} / \mathrm{m} 2)$ for 10 minutes, and were treated with the PDT laser applied at half-fluence (standard power during 42 seconds). One week after PDT, intravitreal BVZ $(1.25 \mathrm{mg} / 0.05 \mathrm{ml})$ was administered, and repeated monthly during a 6 -month period.

BCVA, CMT, and complete funduscopic evaluation were performed monthly from two months before the intervention to 6 months after. ICG-A and FA were performed before and 6 months after combined therapy.

Main outcome measures included BCVA and CMT 6 months after combined PDT+BVZ and monthly BVZ.

\section{Data analysis and statistical methods}

Statistical analysis was performed using the $U$ Mann-Whitney test. Statistical significance was defined as $p<0.05$, Statistical Package for the Social Sciences software version 20.0 (SPSS Inc., Chicago, Illinois, USA) was used for statistical analysis.

\section{Results}

Out of all n-AMD patients with poor response, 11 eyes of 11 patients fulfilled the inclusion criteria and were selected for the analysis. Five were male, and 6 were female, with a mean age of 62 years.

After the assessment of the lesions with ICG-A and FA, six lesions (54.5\%) were classified as PCV, $2(18.2 \%)$ were arteriolized CNVs, and $3(27.3 \%)$ were non-differentiable. No RAP lesions were identified in this case series (Fig. 1).

At baseline (defined as the time of combined PDT-BVZ therapy), mean -logMAR was $0.63(20 / 85)$ and after 6 months of treatment, vision improved to a mean of $0.32(20 / 41)$, which was statistically significant $(p=0.04)$, as can be seen in Figure 2.

Mean CMT at 2 months before the intervention was $479 \mu \mathrm{m}, 1$ month before the intervention $475 \mu \mathrm{m}$, at baseline was $469 \mu \mathrm{m}, 1$ month after $443 \mu \mathrm{m}, 3$ months after $345 \mu \mathrm{m}$ and 6 months after $289 \mu \mathrm{m}$ (Fig. 3). The improvement between baseline and the 6-month follow-up visit was statistically significant $(p=0.01)$. One of our patients had a serous retinal detachment

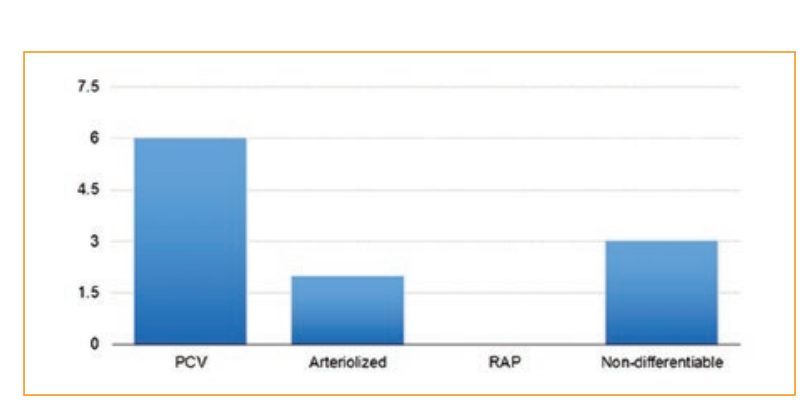

Figure 1. Proportion of patterns recognized using indocyanine green angiography. PCV: polypoidal choroidal vasculopathy. RAP: retinal angiomatous proliferation.

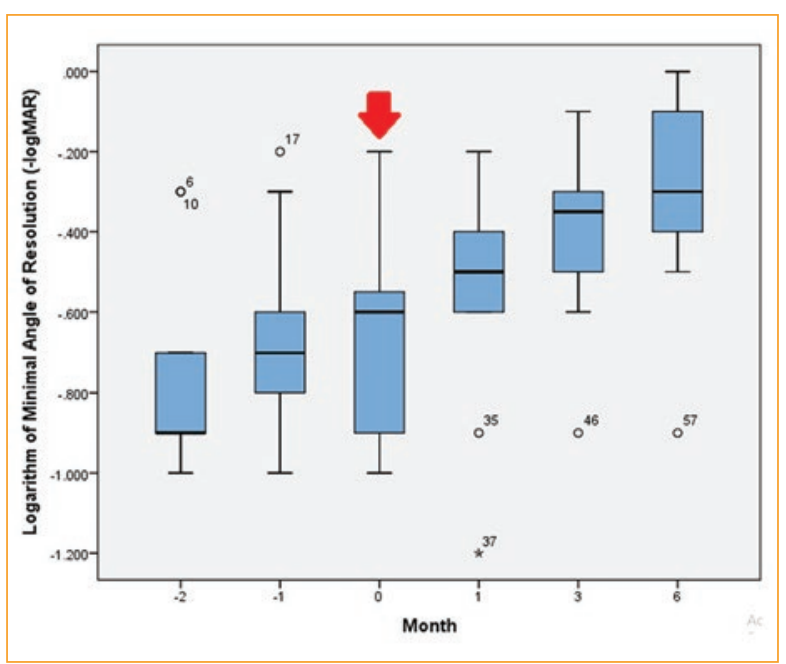

Figure 2. Progression of visual acuity expressed in - $\log M A R$. Red arrow indicates the time where photodynamic therapy was performed.

1 month after the intervention secondary to PDT, which was resolved after periocular injection of betamethasone $(4 \mathrm{mg})$. After resolution of the serous detachment, BCVA and CMT continued to improve.

\section{Discussion}

Anti-VEGF agents are currently the gold standard treatment for CNV secondary to AMD, resulting in significant improvement in BCVA and $\mathrm{CMT}^{2}$. Despite the good overall results with this therapy, some patients fail to achieve a clinically significant response, and are thus labeled "non-responders" or "treatment resistant". These patients usually end up with very poor visual outcomes despite receiving prompt and adequate treatment. The incidence of these treatment-resistant cases is 
unclear, but has been reported as high as $45 \%$ with intravitreal $\mathrm{BVZ}^{10}$. Other type of cases, named "delayed responders", may show an improvement even after 12 months $^{11,12}$.

At this point, the cause of resistance to anti-VEGF therapy is unknown, but one of the theories is related to the degree of maturation of the vessels that compose the CNV. At first, they begin as a capillary-dominated CNV, formed by immature vessels which respond very well to anti-VEGF agents. Nevertheless, whenever pericytes are recruited, the new vessels become feeder vessels, forming an "arteriolized" CNV, which is less responsive to anti-VEGF treatment ${ }^{3}$.

On the other hand, there are other types of CNV that have proven to be resistant to anti-VEGF therapy, such as PCV, or RAP. These lesions [PCV (Fig. 4), RAP and arteriolized CNVs (Fig. 5)] are rarely evident on fluorescein angiography or OCT, but can be readily identified using ICG- $\mathrm{A}^{3}$. In this case series a significant amount (72.6\%) of CNVs classified as treatment-resistant were identified as PCV or arteriolized using ICG-A.

Since these types of lesion are not predominantly capillary and have either mature vessels (RAP and arteriolized CNVs) or are themselves abnormal choroidal vessels (PCV), it makes sense that the response to anti-VEGF agents is suboptimal. It also makes sense to try a different approach that addresses vessels that are non-capillary. Such approach has been attempted successfully in the past with PDT, which uses verteporfin, a benzoporphyrin derivate that in combination with a $689 \mathrm{~nm}$ laser, induces a phototoxic effect.

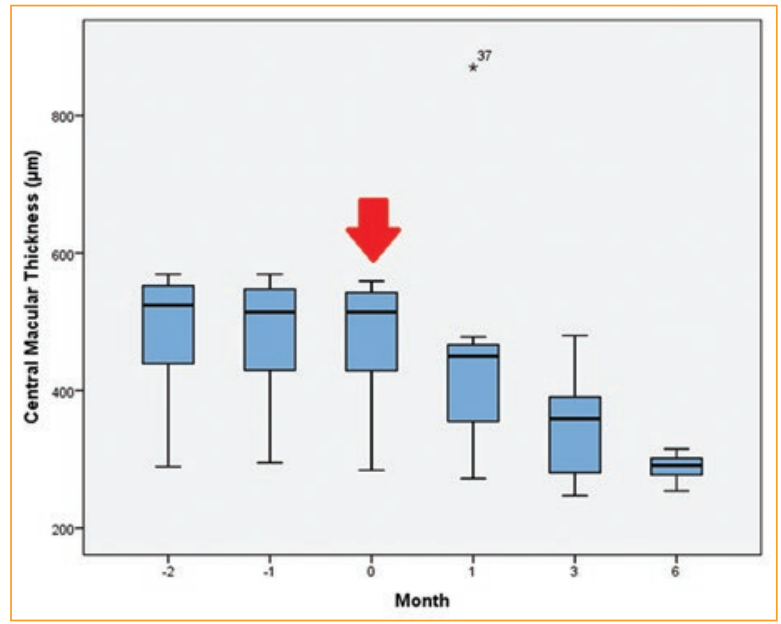

Figure 3. Progression of central macular thickness. Red arrow indicates the time where photodynamic therapy was performed.
It binds to LDL receptors on the endothelial cells causing the destruction of intraluminal cells, therefore inducing thrombosis with subsequent regression of new vessels $^{13}$.

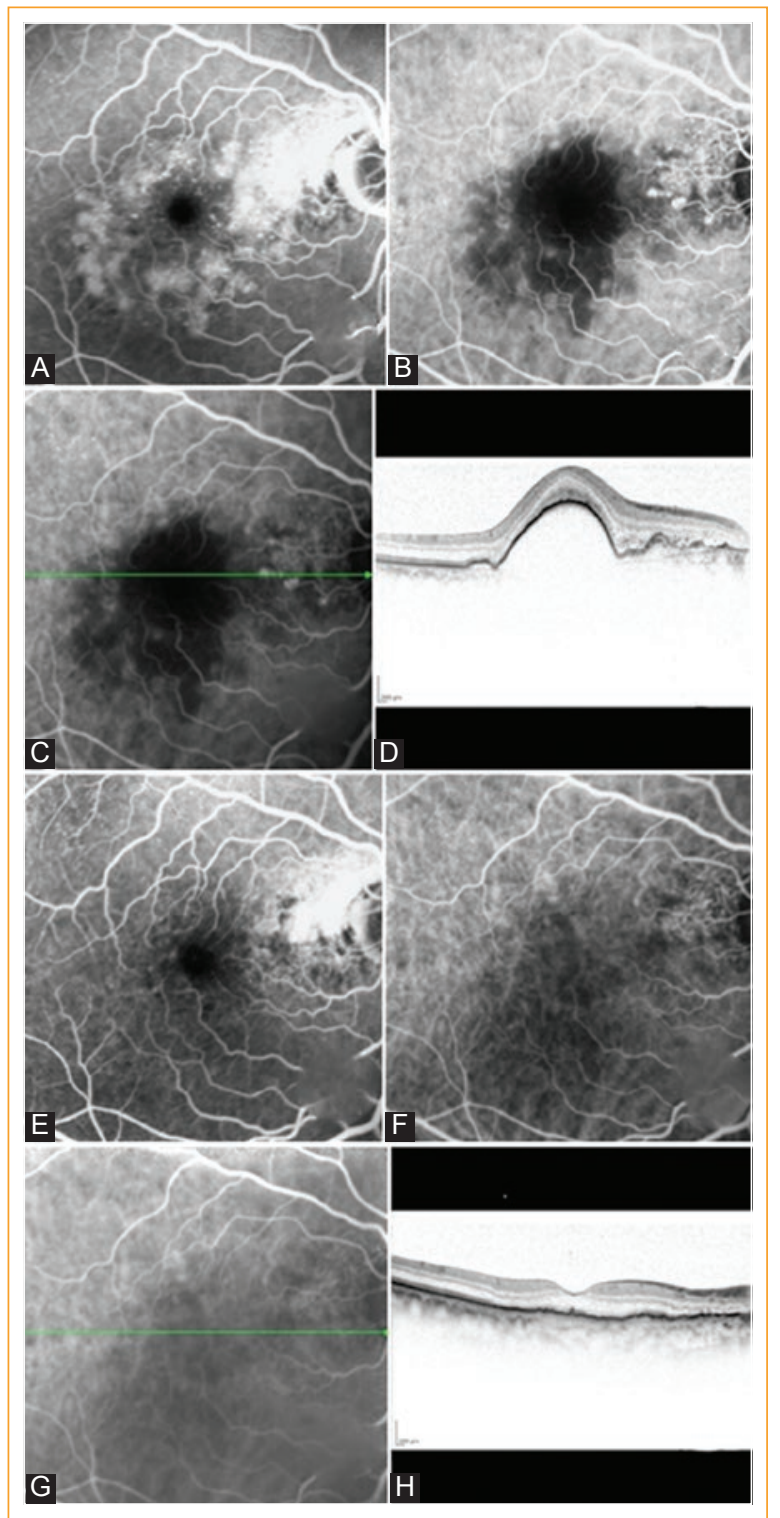

Figure 4. Images of the right eye of a 77 year-old female with polypoidal choroidal vasculopathy. (A) Fluorescein angiogram showing diffuse leakage of undetermined source. (B) Indocyanine green (ICG) angiogram showing yuxtapapillary choroidal polyps. (C) ICG angiogram and (D) OCT showing several large serous pigment epithelial detachments. (E) Fluorescein angiogram showing marked reduction of leakage and (F) ICG angiogram showing disappearance of polyps after combined treatment. (G) ICG angiogram and (E) OCT showing recovery of foveal contour and disappearance of pigment epithelial detachments. Vision improved to $20 / 30$. 


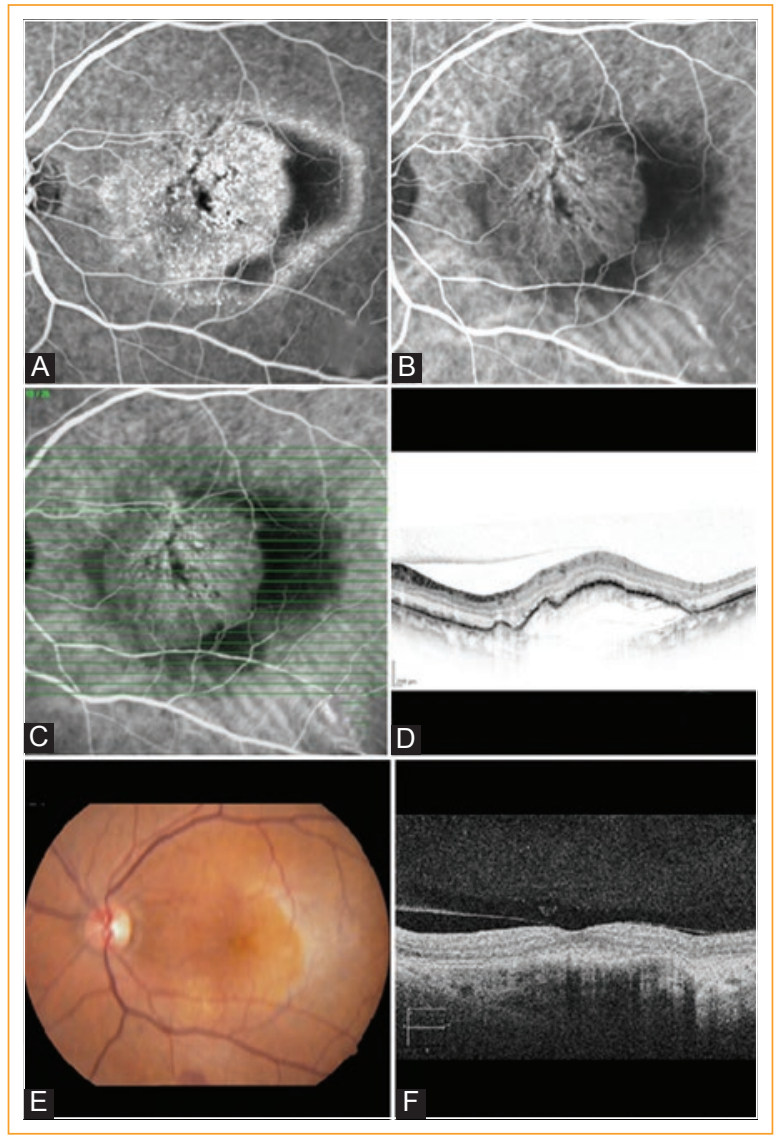

Figure 5. Images of the left eye of a 68 year-old female with arteriolized choroidal neovascular membrane. (A) Fluorescein angiogram showing diffuse leakage of undetermined source. (B) Indocyanine green (ICG) angiogram showing a large neovascular network with a thick vessel in its superior aspect. (C) ICG angiogram. and (D) OCT showing a large fibrovascular pigment epithelial detachment. (E) Fundus image after combined treatment showing a pigment epithelium tear temporal to the fovea. (F) OCT image showing marked reduction of the pigment epithelial detachment.

Photodynamic therapy with verteporfin used to be the standard treatment for $\mathrm{n}-\mathrm{AMD}$, reducing somewhat the visual loss expected without treatment ${ }^{14}$. The situation changed, however, when the ANCHOR study ${ }^{15}$ demonstrated superior visual results with intravitreal RBZ when compared to PDT alone. The FOCUS study ${ }^{16}$ evaluated the combination of PDT plus RBZ versus PDT alone, demonstrating superiority of combination treatment. However, since visual gain with combination therapy in the FOCUS study (4.6 letters) was not superior to the visual gain observed with RBZ alone in the ANCHOR study (6.6 letters), PDT fell quickly in disuse (although no direct comparison of RBZ alone vs RBZ plus PDT was performed at the time).
Even though PDT lost ground to intravitreal anti-VEGF treatment, several studies have since been performed using PDT in combination with anti-VEGF agents, either to reduce the number of intravitreal injections needed or to increase their efficacy in treatment-resistant cases. Such is the case of a study published by Bashsur et al. ${ }^{17}$ that included 40 eyes randomized to either RBZ monotherapy or combined with standard fluence (SF) PDT, showing that patients receiving combination therapy required less injections ( 3 vs. 6 ), but gained significantly less VA ( +3.2 vs. +12 letters). Similar findings were observed by Krebs et al. in 44 patients, also noticing reduced need for intravitreal injections with combined therapy (4.7 vs. 6.3 ) but worse visual outcome $(-7.1 \text { vs. }+5.1 \text { letters })^{18}$. Two other studies (Williams et al. ${ }^{8}$ and Hatz et al. ${ }^{19}$ ) found reduced need for injections but no difference in final VA. The MONTBLANC trial20, with similar design but more patients $(n=253$ ) found no significant difference between number of injections (4.8 vs. 5.1) or VA gain (+2.5 vs. +4.4 letters) among the two groups. A parallet study, the DENALI trial ${ }^{21}$ compared RBZ monotherapy and combined with either SF or reduced fluence (RF) PDT, showing that patients receiving PDT required fewer injections (5.1 and 5.7 versus 10.5 in the monotherapy group), but also gained less visiual acuity $(+5.3$ and +4.4 versus +8.1 in the monotherapy group).

Data in these studies showed that the combination of PDT plus anti-VEGF therapy usually resulted in less requirement of intravitreal injections, but also resulted in less visual gain when compared to anti-VEGF monotherapy. Although there is no clear explanation for this phenomenon, it is probably related to the effect that PDT has over normal choroidal vessels, which might in turn damage retinal cells, therefore impairing visual recovery. However, these studies included eyes that were treatment-naïve, and ICGA was not performed to further identify the type of neovascularization to be treated.

Comparatively, there are few studies that address the use of combined PDT plus anti-VEGF therapy in treatment-resistant cases. A retrospective review of 31 patients treated with anti-VEGF plus PDT plus intravitreal steroids was published by Bakri et al., ${ }^{22}$ and included 18 patients that had been previously treated with anti-VEGF monotherapy, resulting in mild decrease in VA and macular thickness which were not statistically significant. Kloos et al. ${ }^{23}$ also reported the effect of adding PDT to anti-VEGF monotherapy in 18 wet AMD patients, which resulted in fewer injection requirement and stabilization of VA. Tozer et al. ${ }^{6}$ published a retrospective 
series of 26 patients resistant to anti-VEGF monotherapy that were managed with combined PDT plus anti-VEGF when needed, finding that while VA remained approximately the same, macular thickness was significantly reduced, and the proportion of patients with fluid-free maculas increased from $0.5 \%$ to $41 \%$ after combined treatment. The authors hypothesized that the lack of improvement in VA might be related to the amount of time that the disease remained active before initiating combined therapy.

In our study, we observed that after combined PDT plus BVZ therapy there was a significant reduction in macular thickness and also a significant improvement in VA, which has seldom been reported. This difference may be related to the fact that the time to consider that a case was "treatment-resistant" was less than in other studies, and that intravitreal BVZ was mandatory on a monthly basis regardless of the presence of disease activity, which may lead to the theory that perhaps in other studies patients were being undertreated, resulting in suboptimal visual outcome.

Another strength of our study is that ICG angiography was performed in all patients, allowing for the identification of special types of CNV that are typically treatment-resistant, which was not done in other studies. In our case series, the proportion of treatment-resistant cases that ultimately were diagnosed as PCV was high $(54.5 \%)$, which has been described in other studies ${ }^{24}$. This might also account for the good response to treatment in our series, since PDT has proven to be especially useful for the treatment of PCV, as confirmed by the EVEREST and EVEREST II trials ${ }^{4,25}$. We think that the value of ICG angiography is underestimated, and in our current management algorithm, we perform this test if patients have had three intravitreal anti-VEGF injections without significant reduction in macular thickness. If a PCV or arteriolized pattern is observed, PDT is added to continued monthly anti-VEGF injections. We also consider performing the test if the clinical suspicion for PCV is high, e.g., CNV with abundant exudation or hemorrhage, or diagnosis of PCV in the contralateral eye.

This study is limited by its design; it was a retrospective case series and we had a small number of patients. Considering this, the results and conclusions are not applicable to large populations and further studies should be performed to confirm these findings.

\section{Conclusion}

In this small retrospective case series, combined PDT with BVZ is effective for the management of CNV resistant to anti-VEGF monotherapy. Additionally, ICG angiography proved to be a valuable tool to identify lesions that are known to be treatment-resistant.

\section{Ethical disclosures}

Protection of human and animal subjects: The authors declare that no experiments were performed on humans or animals for this study.

Confidentiality of data. The authors declare that they have followed the protocols of their work center on the publication of patient data.

Right to privacy and informed consent: The authors declare that no patient data appear in this article.

\section{Funding}

None.

\section{Conflicts of interest}

Authors have nothing to disclose.

\section{References}

1. Brucker AJ. Age-related macular degeneration. Retina. 2009;29:S2-4.

2. Arevalo JF, Lasave AF, Wu L, et al. Intravitreal bevacizumab for choroidal neovascularization in age-related macular degeneration: 5-year Results of the pan-American collaborative retina study group. Retina. 2016;36:859-67

3. Date A, Koreen L, Hollar MW, Cousins SW. Where do PCV and RAP Fit in the Spectrum of AMD CNV Subtypes? Subtypes: beyond classic and occult. Retin Phys. 2010:1-9.

4. Koh A, Lee WK, Chen LJ, et al. Everest study: efficacy and safety of verteporfin photodynamic therapy in combination with ranibizumab or alone versus ranibizumab monotherapy in patients with symptomatic macular polypoidal choroidal vasculopathy. Retina. 2012;32:1453-64.

5. Stone TW, editor. ASRS 2016 Preferences and Trends Membership Survey. Chicago, IL. American Society of Retina Specialists; 2016.

6. Tozer K, Roller AB, Chong LP, et al. Combination therapy for neovascular age-related macular degeneration refractory to anti-vascular endothelial growth factor agents. Ophthalmology, 2013;120:2029-34.

7. Antoszyk AN, Tuomi L, Chung CY, et al. Ranibizumab combined with verteporfin photodynamic therapy in neovascular age-related macular degeneration (FOCUS): year 2 results. Am J Ophthalmol. 2008;145:862-74

8. Williams PD, Callanan D, Solley W, Avery RL, Pieramici DJ, Aaberg T. A prospective pilot study comparing combined intravitreal ranibizumab and half-fluence photodynamic therapy with ranibizumab monotherapy in the treatment of neovascular age-related macular degeneration. Clin Ophthalmol. 2012;6:1519-25

9. Amoaku WM, Chakravarthy U, Gale R, et al. Defining response to anti-VEGF therapies in neovascular AMD. Eye. 2015;29:721-31.

10. Lux A, Llacer H, Heussen FM, Joussen AM. Non-responders to bevacizumab (Avastin) therapy of choroidal neovascular lesions. $\mathrm{Br} J$ Ophthalmol. 2007;91:1318-22.

11. Tan CS, Ngo WK, Chen JP, Tan NW, Lim TH. Everest study report 2 imaging and grading protocol, and baseline characteristics of a randomised controlled trial of polypoidal choroidal vasculopathy. Br J Ophthalmol. 2015;99:624-8.

12. Stoller GL, Kokame GT, Dreyer RF, Shapiro H, Tuomi LL. Patterns of early and delayed visual response to ranibizumab treatment for neovascular age-related macular degeneration. JAMA Ophthalmol. 2016:134:545-53.

13. Schmidt-erfurth U, Michels S, Barbazetto I, Laqua H. Photodynamic effects on choroidal neovascularization and physiological choroid and physiological choroid. Invest Ophthalmol Vis Sci. 2016;43:830-41. 
Rev Mex Oftalmol (Eng). 2018;92

14. Treatment of Age-Related Macular Degeneration with Photodynamic Therapy (TAP) Study Group. Photodynamic therapy of subfoveal choroida neovascularization in age-related macular degeneration with verteporfin: two-year results of 2 randomized clinical trials-TAP report 2. Arch Ophthalmol. 2001;119:198-207.

15. Brown DM, Michels M, Kaiser PK, et al. Ranibizumab versus verteporfin photodynamic therapy for neovascular age-related macular degeneration: two-year results of the ANCHOR study. Ophthalmology. 2009:116:57-65.

16. Antoszyk AN, Tuomi L, Chung CY, Singh A, FOCUS Study Group. Ranibizumab combined with verteporfin photodynamic therapy in neovascular age-related macular degeneration (FOCUS): year 2 results. Am J Ophthalmol. 2008;145:862-74

17. Bashshur ZF, Schakal AR, El-Mollayess GM, Arafat S, Jaafar D, Salti HI Ranibizumab monotherapy versus single-session verteporfin photodynamic therapy combined with as-needed ranibizumab treatment for the management of neovascular age-related macular degeneration. Retina 2011;31:636-44

18. Krebs I, Marlovits VV, Bodenstorfer J, et al. Comparison of ranibizumab monotherapy versus combination of ranibizumab with photodynamic therapy with neovascular age-related macular degeneration. Acta Ophthalmol. 2013:91:178-83.

19. Hatz K, Schneider U, Henrich PB, Braun B, Sacu S, Prünte C. Ranibizumab plus verteporfin photodynamic therapy in neovascular age-related macular degeneration: 12 months of retreatment and vision outcomes from a randomized study. Ophthalmologica. 2015;233:66-73.

20. Larsen M, Schmidt-Erfurth U, Lanzetta $P$, et al. Verteporfin plus ranibizumab for choroidal neovascularization in age-related macular degeneration: twelve-month MONT BLANC study results. Ophthalmology. 2012;119:992-1000

21. Kaiser PK, Boyer DS, Cruess AF, et al. Verteporfin plus ranibizumab for choroidal neovascularization in age-related macular degeneration: twelve-month results of the DENALI study. Ophthalmology. 2012;119:1001-10.

22. Bakri SJ, Couch SM, McCannel CA, Edwards AO. Same-day triple therapy with photodynamic therapy, intravitreal dexamethasone, and bevacizumab in wet age-related macular degeneration. Retina. 2009;29:573-8.

23. Kloos $P$, Niederberger $H$, Valmaggia $C$. Photodynamic therapy in "secondary sick RPE syndrome" after repeated intravitreal injections of VEGF inhibitors in patients with wet age-related macular degeneration [In German]. Klin Monbl Augenheilkd. 2011;228:340-4.

24. Cho M, Barbazetto IA, Freund KB. Refractory neovascular age-related macular degeneration secondary to polypoidal choroidal vasculopathy. Am J Ophthalmol. 2009;148:70-78.

25. Koh A, Lai TY, Takahashi K, et al. Efficacy and safety of ranibizumab with or without verteporfin photodynamic therapy for polypoidal choroidal vasculopathy: a Randomized clinical trial. JAMA Ophthalmol. 2017; $135: 1206-13$ 